5. Essay on the constitution of the solar system, in which M. Roche attempted to develop the beautiful cosmogonic theory of Laplace, giving precision to certain points and modifying it in others. M. Roche was a Corresponding Mernber of the Academy of Sciences in the Section of Astronomy, and had been nominated as a candidate for the place vacant by the death of $M$. Liouville.

\section{THE LATE MR. W. A. FORBES}

$\mathrm{M}^{\mathrm{R}}$ R. WILLIAM ALEXANDER FORBES, Fellow of St. John's College, Cambridge, Prosector to the Zoological Society of London, and Lecturer on Comparative Anatomy to Charing Cross Hospital, whose untimely death on the Niger we announced last week, was born at Cheltenham on June 24,1855 , the second son of Mr. J. $\mathrm{S}$. Forbes, the well-known railway director. He was educated at Kensington School and Winchester College, which he entered at the early age of eleven. On leaving Winchester in 1872 , Forbes passed a year at Aix-laChapelle studying German, and then became a student of the University of Edinburgh, where he pursued the regular medical course, paying special attention to zoology and botany, and commencing collections of insects and plants. In 1875 Forbes transferred his residence to London, and entered himself as a student of London University with the idea of taking a medical degree in the metropolis. Here he became quickly intimate with other zoologists, who were very soon attracted by the a stounding general knowledge of zoology and the acute intelligence of one so young. By the advice of the late Prof. Garrod and other friends $\mathrm{Mr}$. Forbes was induced in October, 1876, to leave London and to become an undergraduate of St. John's College, Cambridge, where he was subsequently elected Scholar, and took his B.A. degree with a First Class in the Natural Sciences Tripos in 1879 . The post of Prosector to the Zoological Society of London having become vacant in October, 1879 , by the lamented death of Prof. Garrod, Mr. Forbes was appointed (omnium consensu) to that office in the January following. Indeed he had been designated by Garrod on his deathbed as his most obvious and proper successor, and had been appointed his literary executor.

Mr. Forbes entered upon the duties of his office with characteristic energy, and during the three following sessions of the Zoological Society brought before the scientific meetings a series of most interesting and valuable communications derived from his studies of the animals that came under his examination. He had a happy knack of putting forward abstruse points of anatomy in an understandable form, and especially directed himself to the muscular structure and voiceorgans of birds, in continuation of the researches of his predecessor Garrod on the same subjects. In the summer of 1880 Mr. Forbes made a short excursion to the forests of Pernambuco, Brazil, of which he published an account in the $I b i$ s for $188 \mathrm{I}$, and in the following year passed his boliday in the United States, in order to make the acquaintance of his American brethren in science and their collections. In July, i 882, he left England on what promised to be a splendid opportunity of visiting the eastern tropics with every advantage and without much risk. Detained at Shonga-a station some 400 miles up the Niger below Rebba-by the breaking down of his communications, Mr. Forbes fell a victim to dysentery on January 14 last, thus adding another name to the long list of martyrs of science in that deservedly dreaded climate.

Mr. Forbes's published works consist chiefly of papers in the Proceedings of the Zoological Society and the Ibis, altogether about sixty in number. He was editor of the memorial volume of collected scientific papers of his predecessor Garrod, and just before he left England in July last had finished the last sheets of an excellent memoir on the anatomy of the petrels-since published in the "Zoology of the Challenger Expedition." This piece of work was originally undertaken by Garrod, but had been left almost uncommenced at the decease of the latter.

Of Forbes's private qualities as a most efficient and ready fellow-worker, a most charming companion and a most sincere friend, the writer is able to testify, not only from personal experience, but also from the universal regret expressed at the unhappy end of so promising a naturalist.

P. L. S.

\section{RECENT INFLUENCE-MACHINES}

SEVERAL modified types of influence-machine have recently been brought before the public, and as they are both cheaper and more efficient than the older forms of Töpler, Holtz, and Bertsch, will probably find general acceptance. Of the newer forms, those of Voss and of Wimshurst are illustrated in the accompanying cuts.

In the Voss machine, which may be regarded as a modified Töpler machine, there are two disks of varnished glass, one stationary, the other rotating in front of it on an axis which passes through a central hole tbrough the fixed disk. A pair of pulleys with a strap provide the rapid movement necessary. At the back of the fixed disk are fixed two armatures or inductors of varnished paper,

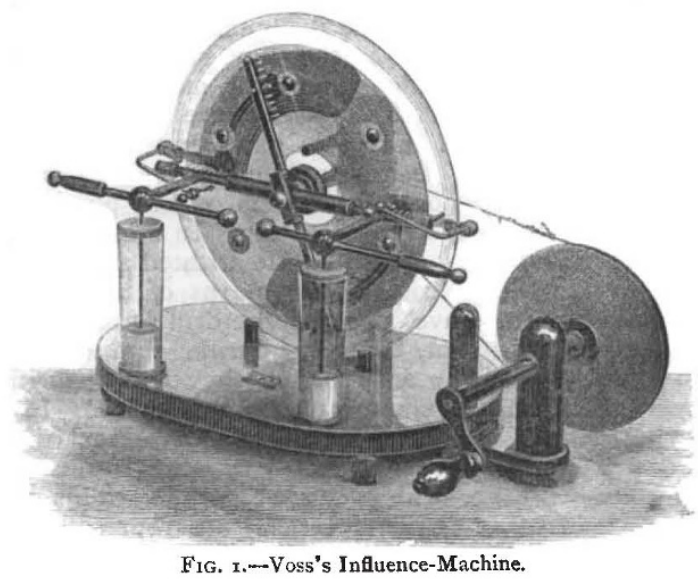

with a narrower central band of tinfoil. These armatures are connected on the right and left respectively with two metal clamps which nip on to the edge of the disk and turn round in front of the front plate, each being provided at this part with a little metallic brush. Upon the front of the rotating plate are fastened six or eight metal buttons at equal intervals. These buttons are touched as they rotate by the metallic brushes. Nearly perpendicular, and in front of the front disk, is a brass rod, which need not be insulated, also furnished with spikes at each end, and with a little metallic brush to touch the buttons of the rotating plate. The action of the machine is as follows:-If a small charge of electricity-say a positive charge - be imparted to one armature - say that on the left - the buttons as they move past will be acted on inductively, and if, while thus under the inductive influence of the positive charge, they are momentarily touched by an uninsulated conductor, they will pass on electrified with a charge of the opposite sign. If the front plate rotates in the clockwise direction, each button as it moves through its highest position towards the right will thus acquire a small negative charge which will be given up on arriving at the right side, the projecting arm conveying the charge to the armature at the back. Bui as the button passes on downwards it will be influenced inductively by the armature behind it, and when touched by the lower end of the vertical conductor, will assume a positive electrification. 